\title{
Design of an Optimally-Diagnostic Skin Test With Fewer Samples for Diagnosis of Sensitivity to Eight Allergens: a First-In-Human Study of Dose Escalation and Simultaneous Administration in Chinese Subjects
}

\section{Xiaoyi Ning}

Central South University Third Xiangya Hospital https://orcid.org/0000-0002-7909-7997

\section{Yun Kuang}

Central South University Third Xiangya Hospital

Shuwei Zhao

Tianjin Medical University General Hospital

\section{Guoping Yang}

Central South University Third Xiangya Hospital

\section{Wenjing Hou}

Tianjin Medical University General Hospital

\section{Chengxian Guo}

Central South University Third Xiangya Hospital Jinlian Xie

Central South University Third Xiangya Hospital

\section{Liying Gong}

Central South University Third Xiangya Hospital

Xuerui Zhu

Zhejiang Wolwo Biopharmaceutical Co., Ltd.

Chang Cui

Central South University Third Xiangya Hospital

\section{Shuang Yang}

Central South University Third Xiangya Hospital

\section{Xiaoyan Yang}

Central South University Third Xiangya Hospital

Chengjun Guo

Central South University Third Xiangya Hospital

Ruiling Liu

Tianjin Medical University General Hospital 


\section{Yuxiang Xiang}

Central South University Third Xiangya Hospital

Jie Huang ( $\nabla$ cellahuang1988@163.com )

https://orcid.org/0000-0002-1945-6353

\section{Research}

Keywords: skin prick test, allergen, optimally diagnostic concentration

Posted Date: August 4th, 2020

DOI: https://doi.org/10.21203/rs.3.rs-51174/v1

License: (c) (1) This work is licensed under a Creative Commons Attribution 4.0 International License.

Read Full License 


\section{Abstract}

Background: Skin prick test is usually the preferred test in the diagnostic workup for allergic diseases, while there are few types of standardized allergen extracts available. Besides, standardization and composition give no assurance that the allergen extracts are within the concentration range that give the best chance of a true diagnosis. We designed a first-in-human diagnostic skin test with fewer samples to identify the optimally diagnostic concentration for eight standardized extracts from frequent native allergens, and to assess the safety of the eight allergens extracts' simultaneous administration for supporting clinical allergen screening.

Methods: Patients aged 18-45 years who had a history of allergic diseases were enrolled in this two-part open-label, parallel study: Study 1, each patient was given three concentrations of one allergen extract in turn. Study 2, each patient was given two concentrations of eight allergens extracts. Negative and positive controls were given each time the allergen was given. Both safety and sensitivity were evaluated to determine the optimally diagnostic concentration. Related-Samples Friedman's Two-Way Analysis was used to evaluate the difference of wheal diameter between different concentrations of each allergen. SPSS Statistics 26 was used for statistical analysis, and the significance test level was 0.05 .

Results: The sensitivity of allergens increased with the increasing of concentration. The eight investigated allergens showed good safety and did not reach the dose limit toxicity whether used alone or in combination. The optimally diagnostic concentration for eight aeroallergens were respectively determined as $33333 \mathrm{DU} / \mathrm{mL}, 12000 \mathrm{DU} / \mathrm{mL}, 8667 \mathrm{DU} / \mathrm{mL}, 50000 \mathrm{DU} / \mathrm{mL}, 40000 \mathrm{DU} / \mathrm{mL}, 3333 \mathrm{DU} / \mathrm{mL}, 7000 \mathrm{DU} / \mathrm{mL}$, and $5000 \mathrm{DU} / \mathrm{mL}$.

Conclusions: This study designed a solution to determine the optimally diagnostic concentration with fewer subjects for further clinical trials of the eight investigated allergens and the results of this phase I clinical trial support further clinical research of investigated allergens.

Trial registration: The trial was registered on www.chictr.org.cn (ChiCTR1900023952, 06/19/2019, retrospectively registered).

\section{Introduction}

The identification of the disease-causing allergens is critical for the accurate diagnosis of Immunoglobulin $\mathrm{E}(\mathrm{lgE})$-associated allergy, which is the most common and important immunologically mediated hypersensitivity disease affecting approximately $30 \%$ of the population worldwide[1-3]. The specific diagnosis of IgE-mediated allergy to aeroallergens is usually based on the correlation between clinical symptoms and medical history supplemented by diagnostic tests such as analyses for circulating specific $\lg \mathrm{E}(\mathrm{slgE})$ antibodies in serum and skin prick test(SPT)[4]. SPT is usually the preferred test in the diagnostic workup for allergic diseases because of its reliability, safety, convenience and low cost[5-7]. 
A wide variety of factors may influence the result of SPTs in clinical practice, in which the quality of allergen extract is of main significance. The composition, total potency, and the size of the SPT reaction can vary, despite being from the same allergen source[8, 9]. Therefore, the availability of a wide range of high-quality allergen extracts is of main significance for reliable results[10]. However, with the standardized requirements of allergen extracts, the reliability of various non-standardized allergen extracts on the market has been questioned[11], while there are few types of reliable standardized allergen extracts available. In some European countries (i.e., Germany), certain extracts are no longer available on the market due to several quality control requirements. And in the United States, there are only 19 of the more than 1000 diagnostic and therapeutic extracts having a standardized potency[12]. As in China, most SPT solutions are hospital preparations. In addition, the standardized allergen extracts product form European or America, though rarely, may not be applicable to Asian. Since the specific allergens responsible for sensitization are different geographically as their nature and number vary with location, temperature, and climate[13]. It is imminent to produce a variety of standardized allergen extracts and apply them to clinical diagnosis.

Besides, standardization and composition alone do not necessarily ensure that allergen extracts used for skin prick testing are of an appropriate concentration to minimize the possibility of false positive and false negative skin reactions[14]. However, there is no standard guideline for pre-market research on diagnostic allergen extracts, and current clinical studies pay less attention to the optimally diagnostic concentration of allergen extracts. The objective of the study was to design a first-in-human diagnostic skin test with fewer samples to identify the optimally diagnostic concentration for eight standardized prick extracts from frequent native allergens (artemisia annua pollen, platanus pollen, humulus pollen, betula platyphylla pollen, ragweed pollen, blattella germanica, cat dander and dog dander) regarding sensitivity and safety in allergic patients. Besides, it also assessed the safety of the eight standardized allergens extracts' simultaneous administration to support clinical allergen screening.

\section{Methods}

\section{Study Population}

Patients aged 18-45 years of both sexes who had a history of allergic diseases were enrolled in the study. Women of childbearing potential should have a negative blood pregnancy $(\beta-H C G)$ test result. Patients were invited for a preliminary assessment to evaluate their serum slgE concentration (UniCAP, Phadia, Sweden) of the eight investigated allergens. For Study 1, patients with the slgE concentration of one of the eight allergens within $0.70 \sim 49.9 \mathrm{KUA} / \mathrm{L}$ were enrolled. For Study 2 patients were requested to have the slgE concentration of at least two kinds of the eight allergens within $0.70 \sim 100 \mathrm{KUA} / \mathrm{L}$. Besides, patients enrolled in Study 1 should pass a SPT of the positive and negative control solution in the "Skin Prick Test Kit for Der.f.(Dermatophagoides Farinae) Detection" (produced by Zhejiang Wolwo Biopharmaceutical Co., Ltd.), the diameter of wheal was $\geq 3 \mathrm{~mm}$ for positive control solution and no wheal for negative control (redness was allowed). 
Key exclusion criteria included the following: people with orthostatic hypotension, a history of halo needles or halo blood, intolerance to pricks, symptoms of angioedema, or contraindications to adrenaline; women during pregnancy or lactation; had severe allergic reactions or anaphylactic shock; with a history of asthma or in the stage of asthma attack; had used antihistamine drugs within 7 days; had used phenothiazine drugs or imipramine antidepressants within 30 days before the trial, or being treated with beta blockers or angiotensin converting enzyme inhibitors; undergone ultraviolet chemotherapy within 30 days; had used glucocorticoids in the forearm within 2 days; with skin scratches; skin infections, dermatitis, pathological changes such as trauma, scars or tattoos on both forearms; with a recent history of drug or alcohol abuse, and use of tobacco or nicotine containing products within 3 months before check-in.

All participants were provided with written informed consent before study initiation. The study protocol was reviewed by the independent Ethics Committee of the Third Xiangya Hospital of Central South University and the ethics committee of Tianjin Medical University General Hospital, and performed in accordance with the principles stated in the Declaration of Helsinki. The trial was registered on www.chictr.org.cn (ChiCTR1900023952, 06/19/2019, retrospectively registered).

\section{Skin Test Material}

Eight different SPT solutions were tested: artemisia annua pollen, platanus pollen, dog dander, betula platyphylla pollen, cat dander, humulus pollen, blattella germanica and ragweed pollen. The test products were provided in vials containing different concentrations of each allergen. Histamine phosphate (1.70 $\mathrm{mg} / \mathrm{mL}$ ) was used as positive control and glycerin saline solution ( $(\mathrm{v}: \mathrm{v}=1: 1)$ as negative control solution. All SPT solutions and positive and negative controls were manufactured by Zhejiang Wolwo Biopharmaceutical Co., Ltd.

\section{Study Design}

\section{Study 1}

Study 1 was conducted as an open-label, parallel study to investigate the effectiveness and tolerance of the subjects to the single allergen within a concentration range at two centers in China. Patients with serum slgE concentration of the allergen within $0.70 \sim 49.9 \mathrm{KUA} / \mathrm{L}$ were enrolled into corresponding allergen groups. SPTs with single allergen and positive and negative controls were performed at the same time and subjects should be followed up to $24 \mathrm{~h}$. After a washout period of 48 hours, the next concentration of SPT solution would be given. The test products contained three different concentrations of each allergen increasing in three-fold steps, and the concentration of each SPT solution were shown in Table 1.

\section{Study 2}

Study 2 was conducted as a single-center, open-label, parallel study to investigate the tolerance of the subjects to the combination of eight allergens at two different concentrations. Patients with the serum 
slgE concentration of at least two kinds of the eight allergens within $0.70 \sim 100 \mathrm{KUA} / \mathrm{L}$ were enrolled. SPTs with both eight allergens and positive and negative controls were performed at the same time and subjects should be followed up to $24 \mathrm{~h}$. Each allergen in Study 2 included two concentrations groups. The optimally diagnostic concentration in Study 1 was selected as Conc. 1 for group 1, and the triple of optimally diagnostic concentration was Conc. 2 for group 2. The two concentrations of each SPT solution were shown in Table 2. The test of Conc. 1 group was started first, and if there was no event that meets the termination criteria, the test of Conc. 2 group was performed.

\section{Skin Prick Test}

SPTs were performed on the volar sides of forearms. The investigated allergens as well as positive and negative controls were tested. The test areas were numbered by means of a suitable skin marker and had a minimum distance of $3 \mathrm{~cm}$ to each other. The skin was pricked lightly and quickly vertically through the drop of the SPT solution by means of a microlancette. For each prick a new microlancette was used.

The test solution was removed in 3 min after the SPT by laying an absorbent paper towel on the skin prick area and carefully pressing it on the skin. The wheal outlines were read after 15-20 min. The wheal outline was traced with a ballpoint pen, then taken off from the patient's skin and documented by sticking them into the grid paper using a broad piece of translucent tape. The average diameter $(Y)$ was recorded as: $Y=(D+d) / 2$, the longest diameter of the wheal was $D$ and the mid-vertical line of the longest diameter was $d$. Then the original wheal area was preserved as a picture. For assessment of a positive SPT reaction, the wheal had to be $\geq 3 \mathrm{~mm}$ in diameter. A valid SPT result also required a positive histamine reaction $(\geq 3 \mathrm{~mm})$ and a negative saline control reaction $(<3 \mathrm{~mm})$ [15].

\section{Estimation of Sensitivity and Optimally diagnostic concentration}

The estimation of sensitivity was carried out in Study 1 . The number of patients with a positive SPT result at different concentrations of each allergen was counted to calculate the positive rate of each allergen at different concentrations, i.e. the sensitivity of the allergen. The sensitivity was estimated by the number of patients with a positive SPT result (diameter of wheal $\geq 3 \mathrm{~mm}$ ) divided by the number of all patients with a valid SPT result. And the optimally diagnostic concentration for each allergen was investigated by determination of sensitivity for each concentration of eight allergens based on safety. Besides, the diameter of wheal at different concentrations of each allergen was compared to evaluate the relationship between allergen exposure and allergic reaction.

\section{Safety Assessments}

Both Study 1 and Study 2 were included in safety analysis. Safety assessments included physical examination, vital signs, 12-lead ECGs, routine hematology urinary and chemistry laboratory measurements. Besides, adverse events (AEs) were monitored throughout the study and were evaluated by investigators in terms of intensity, duration, severity, outcomes, and association with the investigated allergen extracts. 
The wheal or itchy that appeared in prick area within 24 hours after the prick test was not considered as an $\mathrm{AE}$, while it would be recorded as an $\mathrm{AE}$ related to allergen if the above phenomenon still exists after 24 hours.

\section{Statistical Analysis}

Sensitivity and safety analysis were planned to be descriptive. The safety population consisted of all patients exposed to any investigated allergens. All patients with a valid SPT result in Study 1 were evaluated for sensitivity analysis. The sensitivity for each concentration of eight allergens was estimated by the number of patients with a positive SPT result divided by the number of all patients with a valid SPT assessment. A valid SPT assessment required a positive histamine reaction ( $\geq 3 \mathrm{~mm}$ ) and a negative saline control reaction $(<3 \mathrm{~mm})$, and a positive SPT result additionally required a wheal with the diameter $\geq 3 \mathrm{~mm}$. Related-Samples Friedman's Two-Way Analysis was used to evaluate the difference of wheal diameter between different concentrations of each allergen. SPSS Statistics 26 was used for statistical analysis, and the significance test level was 0.05 .

\section{Results}

\section{Subjects}

Study 1was conducted between July 09, 2018 and March 01, 2019. As shown in Figure 1, a total of 92 patients were randomized, of which 90 received at least one SPT of investigated allergens in Study 1. And one terminated after the first SPT for the wheal did not subside after 48 hours. The subjects ranged in age from 18 to 42 years and had a mean (SD) body mass index (BMI) of $23.90(3.33) \mathrm{kg} / \mathrm{m}^{2}$. The baseline characteristics of the subjects included in Study 1 were given in Table 3. Of all the 90 subjects, except for one subject in group $D$, for whom the wheal did not subside after receiving the prick test of Conc. 1 for 48 hours and no subsequent concentration test was performed, all other subjects received the prick test of all the three concentrations.

A further 20 subjects were included and completed in Study 2 (Figure 2) from July 16, 2019 to September 14,2019 . Age ranged from 18 to 38 years and the mean (SD) BMI was $22.33(3.16) \mathrm{kg} / \mathrm{m}^{2}$. The baseline characteristics of the subjects included in Study 2 are given in Table 4.

\section{Estimation of Sensitivity and Optimally diagnostic concentration}

The sensitivity of each allergen at different concentrations was outlined in Table 5. Among them, the positive rates of dog dander and humulus pollen were $100 \%$ at all three concentrations. The positive rates of Artemisia annua pollen, cat dander and blattella germanica were $100 \%$ at Conc. 2 and Conc. 3 , as well as $91.67 \%, 75.00 \%$ and $54.55 \%$ at Conc. 1 respectively. The positive rates of platanus pollen were $36.36 \%$, $91.67 \%$ and $100 \%$ respectively, betula platyphylla pollen were $72.73 \%, 80.00 \%$ and $100 \%$ respectively and ragweed pollen were $30.00 \%, 91.67 \%$ and $72.73 \%$ respectively. Based on safety and sensitivity, the 
optimally diagnostic concentrations for each allergen were respectively $33333 \mathrm{DU} / \mathrm{mL}, 12000 \mathrm{DU} / \mathrm{mL}$, $8667 \mathrm{DU} / \mathrm{mL}, 50000 \mathrm{DU} / \mathrm{mL}, 40000 \mathrm{DU} / \mathrm{mL}, 3333 \mathrm{DU} / \mathrm{mL}, 7000 \mathrm{DU} / \mathrm{mL}$, and $5000 \mathrm{DU} / \mathrm{mL}$.

Comparative analysis of the diameter of wheal at different concentrations of eight allergens (Table 6) showed that, except for Dog dander, of which the sample size was too small, the other seven allergens all showed significant differences in the diameter of the wheal at different concentrations. The results of multiple comparisons showed that the wheal size of artemisia annua pollen increased with the increase of concentration. While significant differences were only observed between Group 1 and Group 2, Group 1 and Group 3囚but not Group 2 and Group 3 in other six allergen extracts. The comparison of the diameter of wheal at different concentrations of each allergen were shown in Figure 3.

\section{Safety Assessments}

\section{Study 1}

The incidence of AEs possibly related to allergen in Study 1 was summarized in Additional file 1. 43 of 90 patients (47.8\%) experienced at least one AE possibly related to allergen. As outlined in Additional file 1, the most common AEs (occurring in more than $10 \%$ of 90 patients) possibly related to investigated allergens were urticaria (11.1\%) and itchy $(11.1 \%)$ of the skin prick area, as well as pruritus $(18.9 \%)$ and urticaria (20.0\%). And the common AEs appearing in the eight allergens were essentially similar. AEs occurred in all groups were grade 1 and there was no serious AEs possibly related to investigated allergens, thus no subjects withdrew due to AEs. There was no obvious concentration correlation of the safety of allergen extracts between three concentrations.

At all the three concentrations of each allergen, more than $87.8 \%$ of the subjects' wheal resolved within 24 hours after the test and more than $91.1 \%$ of the subjects did not feel other discomfort.

\section{Study 2}

The incidence of AEs possibly related to allergen in Study 2 was summarized in Additional file 2.15 of 20 patients (75.0\%) experienced at least one AE possibly related to allergen: 7 of 10 patients $(70.0 \%)$ in Group 1 and 8 of 10 patients (80.0\%) in Group 2. As outlined in Additional file 2, the common AEs included urticaria $(40.0 \%)$, itchy $(35.0 \%)$, erythema $(20.0 \%)$ and papule $(20.0 \%)$ of the skin prick area. Of

all the AEs that occurred, except for an allergic dermatitis occurred in Group 2 was determined as grade 2, the others were all grade 1 and no subjects withdrew due to AEs.

In Study 2, 10 wheals of 8 subjects did not subside 24 hours after SPT: two subjects each had one in Group 1; two subjects each had two and four subjects each had one in Group 2, the types of allergens involved were shown in Table 7.

\section{Discussions}


The diagnostic value of an allergen extract can only be assessed with respect to a population consisting of sensitized (true positive) and non-sensitized (true negative) patients[16]. Considering the difference between the sensitivity of non-sensitized and sensitized patients to allergens, we decided to take only sensitized patients as subjects in this first-in-human study. In current medical practice, analyses for circulating slgE antibodies in serum as well as the clinical history and SPT are considered to be standard methods to differentiate sensitized from non-sensitized patients[17, 18], and to confirm the clinical relevance of the allergen in question. Due to the lack of standardized allergen extracts to get the reliable results of SPT, we used medical history and serum slgE detection as the inclusion criteria for sensitized subjects. However, the inclusion of sensitized subjects alone also led to a limitation that we could only investigate the sensitivity of allergens but not their specificity in this study. An assessment of specificity may need to be verified in further clinical trial with more subjects.

Study 1 was the first-in-human trial of investigated allergen extracts, so each allergen extract was planned to include 12 little number of subjects and a total of 96 subjects were planned to be included. However, it was found that there was less allergy to dog dander, resulting in only 6 subjects enrolled into Group C. Dog dander allergen showed excellent sensitivity in all 6 subjects at different concentrations, thus we did not expand the sample.

The initial dose and dose gradient of each allergen were determined using the derivation of human equivalent dose (HED) and based on the no observable adverse effect level (NOAEL) of animal toxicology test. Taking the commonly safety factor 10 as the benchmark, the maximum recommended starting dose (MRSD) was set as HED/10. The minimum dose (Conc.1 of each allergen in Study 1) should be less than MRSD, and the maximum dose (Conc.3 of each allergen in Study 1) less than HED.

The 'average diameter method' was used to characterize the wheal size in this study. Recently, another new method 'scanned area method' has been applied for the actual size[16, 19]. Van der Valk[20] evaluated the two methods and found that the 'scanned area method' may be theoretically more accurate in determining the wheal area than the 'average diameter method' and was recommended in academic research. However, in clinical practice, the 'average diameter method' was also useful, for providing similar accuracy in predicting allergic reactions.

The analysis of the sensitivity of each allergen at different concentrations showed that the positive rates of seven allergen extracts were higher than $80 \%$ at middle and high concentrations, except for ragweed pollen, of which the positive rate was $72.73 \%$ at high concentration. The decrease in sensitivity of ragweed pollen from middle concentration group to high concentration group might be an error caused by the small sample size. Based on safety and sensitivity, the optimally diagnostic concentrations for eight aeroallergens artemisia annua pollen, platanus pollen, dog dander, betula platyphylla pollen, cat dander, humulus pollen, blattella germanica and ragweed pollen were respectively determined as $33333 \mathrm{DU} / \mathrm{mL}$, $12000 \mathrm{DU} / \mathrm{mL}, 8667 \mathrm{DU} / \mathrm{mL}, 50000 \mathrm{DU} / \mathrm{mL}, 40000 \mathrm{DU} / \mathrm{mL}, 3333 \mathrm{DU} / \mathrm{mL}, 7000 \mathrm{DU} / \mathrm{mL}$, and $5000 \mathrm{DU} / \mathrm{mL}$. And the optimally diagnostic concentrations have been used in Phase III clinical trials. The analysis of the diameter of wheal at different concentrations showed that, the wheal size in middle concentration group 
and high concentration group were larger than in low concentration group, while there was no difference between middle concentration group and high concentration group. It suggested that the wheal size might be concentration-dependent within a concentration range, but the wheal size no longer increase when it reached to a certain concentration, which was also consistent with the similar sensitivity between the middle and high concentration groups. It indicated that the sensitivity of allergen extract was affected by its concentration and reflected the importance of finding an appropriate concentration when both sensitivity and safety need to be guaranteed.

At present, there are no studies to comprehensively evaluate the safety of allergen diagnostic skin test in human. Since SPT is similar to Allergen-Specific Immunotherapy (ASIT) in the mechanism of action, we formulated the assessment plan for the safety of allergen extracts referring to the assessment of the safety of ASIT[21] and the instructions of allergen extracts. From the results of Study 1 and Study 2, the eight investigated allergens showed good safety even at high concentration and did not reach the dose limit toxicity whether used alone or in combination. Judging from the situation that the wheals did not completely resolve at $24 \mathrm{~h}$ after SPT in Study 2, except for artemisia annua pollen and humulus pollen, of which the safety in Group 1 may be better than that in Group 2, the safety of other allergen extracts showed no significant difference between two groups. Due to the fewer sample size in Study 2, it is not enough to give a definitive conclusion of safety. A larger sample size is necessary to further confirm the effectiveness and safety of the combination of allergen extracts, evaluate the relationship between benefits and risks in the follow-up clinical trials and finally support the clinical application of allergen extracts.

\section{Conclusion}

As there are no more pre-market clinical research studies or guidelines for diagnostic allergen extracts, this study designed a solution to determine the optimally diagnostic concentration with fewer subjects for further clinical studies of the eight investigated allergens. Besides, the safety of the simultaneous administration of eight allergens also promotes its clinical practice in clinical allergen screening. Of course, it is still necessary to conduct an evaluation of effectiveness and safety in more patients before putting the eight diagnostic reagents in clinical practice. The results of this phase I clinical trial support further clinical research of investigated allergens and the optimally diagnostic concentrations have been used in the Phase III clinical trials of eight allergens.

\section{List Of Abbreviations}

IgE: Immunoglobulin E

slgE: Specific Immunoglobulin E

SPT: Skin prick test

Conc.: Concentration 
ECG: Electrocardiogram

AE: Adverse event

BMl: Body mass index

ASIT: Allergen-Specific Immunotherapy

HED: Human equivalent dose

MRSD: Maximum recommended starting dose

\section{Declarations}

\section{Ethics approval and consent to participate}

All participants were provided with written informed consent before study initiation. The study protocol was reviewed by the independent Ethics Committee of the Third Xiangya Hospital of Central South University $(18029,19069)$ and the ethics committee of Tianjin Medical University General Hospital (IRB2018-077-01), and performed in accordance with the principles stated in the Declaration of Helsinki.

\section{Consent for publication}

Not applicable.

\section{Availability of data and materials}

The datasets generated and/or analysed during the current study are not publicly available due to privacy or ethical restrictions but are available from the corresponding author on reasonable request.

\section{Competing interests}

The authors declare that they have no conflict of interest.

\section{Funding}

This study was supported by Zhejiang Wolwo Biopharmaceutical Co., Ltd., the National Natural Science Foundation of China (No.81673519), National major new drug creation project of China (No.2020ZX09201010) and Natural Science Foundation of Guangdong Province (20181015528).

\section{Authors' contributions}

All authors contributed to the study conception and design. Drafting of the manuscript: $X N, Y K, Y X$. Critical revision of the manuscript for important intellectual content: $X N, Y K, G Y, C G, L G, X Z, R L, J H$. Statistical analysis: XN, YK, SZ, WH, JX, CG. Study supervision: XN, YK, JH, XZ, CC, SY, XY. All authors 
agreed to be accountable for all aspects of the work in ensuring that questions related to the accuracy or integrity of any part of the work are appropriately investigated and resolved.

\section{Acknowledgements}

We would like to thank all trial participants including patients, clinicians, investigators, technician, and nurses.

\section{References}

1. Anto JM, Bousquet J, Akdis M, Auffray C, Keil T, Momas I, et al. Mechanisms of the Development of Allergy (MeDALL): Introducing novel concepts in allergy phenotypes. J Allergy Clin Immunol. 2017;139:388-99.

2. Valenta R, Karaulov A, Niederberger V, Gattinger P, van Hage M, Flicker S, et al. Molecular Aspects of Allergens and Allergy. Adv Immunol. 2018;138:195-256.

3. Larche M, Akdis CA, Valenta R. Immunological mechanisms of allergen-specific immunotherapy. Nat Rev Immunol. 2006;6:761-71.

4. Bousquet J, Heinzerling L, Bachert C, Papadopoulos NG, Bousquet PJ, Burney PG, et al. Practical guide to skin prick tests in allergy to aeroallergens. Allergy. 2012;67:18-24.

5. Bernstein IL, Li JT, Bernstein DI, Hamilton R, Spector SL, Tan R, et al. Allergy diagnostic testing: an updated practice parameter. Ann Allergy Asthma Immunol. 2008;100:1-148.

6. Frati F, Incorvaia C, Cavaliere C, Di Cara G, Marcucci F, Esposito S, et al. The skin prick test. J Biol Regul Homeost Agents. 2018;32:19-24.

7. Ansotegui IJ, Melioli G, Canonica GW, Caraballo L, Villa E, Ebisawa M, et al. IgE allergy diagnostics and other relevant tests in allergy, a World Allergy Organization position paper. World Allergy Organ J. 2020;13:100080.

8. Rueff F, Bergmann KC, Brockow K, Fuchs T, Grubl A, Jung K, et al. [Skin tests for diagnostics of allergic immediate-type reactions. Guideline of the German Society for Allergology and Clinical Immunology]. Pneumologie. 2011;65:484-95.

9. Kleine-Tebbe J, Matricardi PM, Hamilton RG. Allergy Work-Up Including Component-Resolved Diagnosis: How to Make Allergen-Specific Immunotherapy More Specific. Immunol Allergy Clin North Am. 2016;36:191-203.

10. Klimek L, Hoffmann HJ, Renz H, Demoly P, Werfel T, Matricardi PM, et al. Diagnostic test allergens used for in vivo diagnosis of allergic diseases are at risk: a European Perspective. Allergy. 2015;70:1329-31.

11. van Kampen V, de Blay F, Folletti I, Kobierski P, Moscato G, Olivieri M, et al. EAACI position paper: skin prick testing in the diagnosis of occupational type I allergies. Allergy. 2013;68:580-4.

12. Slater JE, Menzies SL, Bridgewater J, Mosquera A, Zinderman CE, Ou AC, et al. The US Food and Drug Administration review of the safety and effectiveness of nonstandardized allergen extracts. $J$ 
Allergy Clin Immunol. 2012;129:1014-9.

13. Bousquet PJ, Chinn S, Janson C, Kogevinas M, Burney P, Jarvis D, et al. Geographical variation in the prevalence of positive skin tests to environmental aeroallergens in the European Community Respiratory Health Survey I. Allergy. 2007;62:301-9.

14. Wheeler AW, Jessberger B, Drachenberg KJ, Rakoski J. Design of an optimally-diagnostic skin test solution for diagnosis of sensitivity to timothy grass (Phleum pratense) pollen. Clin Exp Allergy. 1996;26:897-902.

15. Heinzerling L, Mari A, Bergmann KC, Bresciani M, Burbach G, Darsow U, et al. The skin prick test European standards. Clin Transl Allergy. 2013;3:3.

16. Wagner N, Rudert M. Sensitivity and specificity of standardised allergen extracts in skin prick test for diagnoses of IgE-mediated respiratory allergies. Clin Transl Allergy. 2019;9:8.

17. Szeinbach SL, Barnes JH, Sullivan TJ, Williams PB. Precision and accuracy of commercial laboratories' ability to classify positive and/or negative allergen-specific IgE results. Ann Allergy Asthma Immunol. 2001;86:373-81.

18. Williams PB, Barnes JH, Szeinbach SL, Sullivan TJ. Analytic precision and accuracy of commercial immunoassays for specific IgE: establishing a standard. J Allergy Clin Immunol. 2000;105:1221-30.

19. Sander I, Fleischer C, Meurer U, Bruning T, Raulf-Heimsoth M. Allergen content of grass pollen preparations for skin prick testing and sublingual immunotherapy. Allergy. 2009;64:1486-92.

20. van der Valk JP, Gerth van Wijk R, Hoorn E, Groenendijk L, Groenendijk IM, de Jong NW. Measurement and interpretation of skin prick test results. Clin Transl Allergy. 2015;6:8.

21. Alvarez-Cuesta E, Bousquet J, Canonica GW, Durham SR, Malling HJ, Valovirta E, et al. Standards for practical allergen-specific immunotherapy. Allergy. 2006;61(Suppl 82):1-20.

\section{Tables}


Table 1

The concentrations increased in threefold steps of each allergen in Study 1

\begin{tabular}{|llll|}
\hline Allergen & Conc.1(DU/mL) & Conc.2(DU/mL) & Conc.3(DU/mL) \\
\hline Artemisia annua pollen (Group A) & 33333 & 100000 & 300000 \\
\hline Platanus pollen (Group B) & 4000 & 12000 & 36000 \\
\hline Dog dander (Group C) & 8667 & 26000 & 78000 \\
\hline Betula platyphylla pollen (Group D) & 16667 & 50000 & 150000 \\
\hline Cat dander (Group E) & 13333 & 40000 & 120000 \\
\hline Humulus pollen (Group F) & 3333 & 10000 & 30000 \\
\hline Blattella germanica (Group G) & 2333 & 7000 & 21000 \\
\hline Ragweed pollen (Group H) & 1667 & 5000 & 15000 \\
\hline
\end{tabular}

Table 2

The two concentrations of each allergen in Study 2

\begin{tabular}{|lll|}
\hline Allergen & Group 1(DU/mL) & Group 2(DU/mL) \\
\hline Artemisia annua pollen & 33333 & 100000 \\
\hline Platanus pollen & 12000 & 36000 \\
\hline Dog dander & 8667 & 26000 \\
\hline Betula platyphylla pollen & 50000 & 150000 \\
\hline Cat dander & 40000 & 120000 \\
\hline Humulus pollen & 3333 & 10000 \\
\hline Blattella germanica & 7000 & 21000 \\
\hline Ragweed pollen & 5000 & 15000 \\
\hline
\end{tabular}


Table 3

Demographics of the subjects in Study 1

\begin{tabular}{|c|c|c|c|c|c|c|c|c|c|}
\hline Characterist & $\begin{array}{c}\text { Group A } \\
(n=12)\end{array}$ & 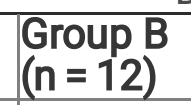 & $\begin{array}{l}\text { Group C } \\
(n=6)\end{array}$ & $\begin{array}{l}\text { Group D } \\
(n=12)\end{array}$ & $\begin{array}{l}\text { Group E } \\
(n=12)\end{array}$ & $\begin{array}{l}\text { Group F } \\
(n=12)\end{array}$ & $\begin{array}{l}\text { Group G } \\
(n=12)\end{array}$ & $\begin{array}{l}\text { Group H } \\
(n=12)\end{array}$ & $\begin{array}{l}\text { Total } \\
(n=90)\end{array}$ \\
\hline Age, years & & & & & & & & & \\
\hline Mean \pm SD & $\begin{array}{l}29.75 \pm \\
5.34\end{array}$ & $\begin{array}{l}29.42 \pm \\
6.20\end{array}$ & $\begin{array}{l}24.17 \pm \\
4.02\end{array}$ & $\begin{array}{l}28.42 \pm \\
6.99\end{array}$ & $\begin{array}{l}26.33 \pm \\
7.70\end{array}$ & $\begin{array}{l}28.33 \pm \\
5.79\end{array}$ & $\begin{array}{l}25.83 \pm \\
6.51\end{array}$ & $\begin{array}{l}25.75 \pm \\
6.17\end{array}$ & $\begin{array}{l}27.46 \pm \\
6.30\end{array}$ \\
\hline Range & $24-39$ & $20-38$ & $20-29$ & $19-40$ & $18-42$ & $19-37$ & $18-38$ & $19-37$ & $18-42$ \\
\hline Gender n (\%) & & & & & & & & & \\
\hline \begin{tabular}{|l} 
Male \\
Female \\
\end{tabular} & \begin{tabular}{|l|}
$8(66.7 \%)$ \\
$4(33.3 \%)$ \\
\end{tabular} & $\begin{array}{l}7(58.3 \%) \\
5(41.7 \%)\end{array}$ & $\begin{array}{l}2(33.3 \%) \\
4(66.7 \%)\end{array}$ & $\begin{array}{l}8(66.7 \%) \\
4(33.3 \%)\end{array}$ & $\begin{array}{l}8(66.7 \%) \\
4(33.3 \%) \\
\end{array}$ & $\begin{array}{l}6(50.0 \%) \\
6(50.0 \%) \\
\end{array}$ & \begin{tabular}{|l|}
$6(50.0 \%)$ \\
$6(50.0 \%)$
\end{tabular} & $\begin{array}{l}2(16.7 \%) \\
10(83.3 \%\end{array}$ & $\begin{array}{l}47(52.2 \%) \\
43(47.8 \%)\end{array}$ \\
\hline Height, cm & & & & & & & & & \\
\hline Mean \pm SD & $\begin{array}{l}170.71 \pm \\
9.47\end{array}$ & $\begin{array}{l}168.71 \pm \\
9.32\end{array}$ & \begin{tabular}{|l}
$164.83 \pm$ \\
11.19
\end{tabular} & $\begin{array}{l}167.50 \pm \\
10.24\end{array}$ & $\begin{array}{l}170.21 \pm \\
10.18\end{array}$ & $\begin{array}{l}167.25 \pm \\
5.29\end{array}$ & $\begin{array}{l}164.92 \pm \\
11.48\end{array}$ & $\begin{array}{l}162.21 \pm \\
6.00\end{array}$ & $\begin{array}{l}167.19 \pm \\
9.30\end{array}$ \\
\hline Range & $\begin{array}{l}154.0- \\
183.0\end{array}$ & $\begin{array}{l}154.0- \\
180.0\end{array}$ & $\begin{array}{l}145.5- \\
176.0\end{array}$ & $\begin{array}{l}147.5- \\
180.0\end{array}$ & $\begin{array}{l}155.0- \\
183.5\end{array}$ & $\begin{array}{l}157.0- \\
175.0\end{array}$ & $\begin{array}{l}152.0- \\
186.0\end{array}$ & $\begin{array}{l}154.5- \\
172.0\end{array}$ & $\begin{array}{l}145.5- \\
186.0\end{array}$ \\
\hline Weight, kg & & & & & & & & & \\
\hline Mean \pm SD & $\begin{array}{l}75.73 \pm \\
17.39\end{array}$ & $\begin{array}{l}68.00 \pm \\
13.66\end{array}$ & $\begin{array}{l}67.15 \pm \\
14.03\end{array}$ & $\begin{array}{l}67.03 \pm \\
11.22\end{array}$ & $\begin{array}{l}70.44 \pm \\
15.05\end{array}$ & $\begin{array}{l}66.32 \pm \\
7.63\end{array}$ & $\begin{array}{l}64.57 \pm \\
13.47\end{array}$ & $\begin{array}{l}58.41 \pm \\
9.32\end{array}$ & $\begin{array}{l}67.21 \pm \\
13.35\end{array}$ \\
\hline Range & $\begin{array}{l}50.1- \\
108.0\end{array}$ & $\begin{array}{l}49.6- \\
88.1\end{array}$ & $\begin{array}{l}44.9- \\
89.1\end{array}$ & $\begin{array}{l}47.7- \\
90.7\end{array}$ & $\begin{array}{l}48.7- \\
103.5\end{array}$ & $\begin{array}{l}51.1- \\
78.9\end{array}$ & $\begin{array}{l}49.4- \\
88.1\end{array}$ & $45.4-73$. & $\begin{array}{l}74.9- \\
108.0\end{array}$ \\
\hline $\mathrm{BMI}, \mathrm{k}$ & & & & & & & & & \\
\hline Mean \pm SD & $\begin{array}{l}25.73 \pm \\
4.10\end{array}$ & $\begin{array}{l}23.76 \pm \\
3.54\end{array}$ & $\begin{array}{l}24.47 \pm \\
2.80\end{array}$ & $\begin{array}{l}23.87 \pm \\
3.15\end{array}$ & $\begin{array}{l}24.18 \pm \\
3.73\end{array}$ & $\begin{array}{l}23.74 \pm \\
2.79\end{array}$ & $\begin{array}{l}23.54 \pm \\
2.85\end{array}$ & $\begin{array}{l}22.17 \pm \\
3.09\end{array}$ & $\begin{array}{l}23.90 \pm \\
3.33\end{array}$ \\
\hline Range & $\begin{array}{l}19.30- \\
32.60 \\
\end{array}$ & $\begin{array}{l}18.30- \\
30.50 \\
\end{array}$ & $\begin{array}{l}21.20- \\
28.80\end{array}$ & $\begin{array}{l}18.80- \\
29.30\end{array}$ & $\begin{array}{l}19.60- \\
30.90 \\
\end{array}$ & $\begin{array}{l}17.30- \\
27.80\end{array}$ & $\begin{array}{l}20.20- \\
29.80\end{array}$ & $\begin{array}{l}17.40- \\
26.60 \\
\end{array}$ & $\begin{array}{l}17.30- \\
32.60\end{array}$ \\
\hline
\end{tabular}

Table 4

Demographics of the subjects in Study 2

\begin{tabular}{|c|c|c|c|}
\hline Characteris & Group 1 ( $n=1$ & Group 2 ( $n=10$ & Total $(n=20)$ \\
\hline Age, years & & & \\
\hline Mean \pm SD & $25.30 \pm 5.73$ & $25.30 \pm 7.02$ & $25.30 \pm 6.24$ \\
\hline Range & $20-36$ & $18-38$ & $18-38$ \\
\hline Gender n(\%) & & & \\
\hline Male & $4(40 \%)$ & $3(30 \%)$ & $7(35 \%)$ \\
\hline Female & $6(60 \%)$ & $7(70 \%)$ & $13(65 \%)$ \\
\hline Height, cm & & & \\
\hline Mean \pm SD & $167.60 \pm 9.57$ & $165.25 \pm 8.88$ & $166.43 \pm 9.07$ \\
\hline Range & $152.0-181.5$ & $155.5-184.5$ & $152.0-184.5$ \\
\hline Weight, kg & & & \\
\hline Mean \pm SD & $64.32 \pm 12.94$ & $60.20 \pm 12.28$ & $62.26 \pm 12.46$ \\
\hline Range & $45.6-80.5$ & $44.7-79.3$ & $44.7-80.5$ \\
\hline $\mathrm{BMI}, \mathrm{kg} / \mathrm{m}^{2}$ & & & \\
\hline Mean \pm SD & $22.76 \pm 3.40$ & $21.89 \pm 3.01$ & $22.33 \pm 3.16$ \\
\hline Range & $17.7-28.6$ & $18.3-25.8$ & $17.7-28.6$ \\
\hline
\end{tabular}


Table 5

The sensitivity of each allergen at different concentrations

\begin{tabular}{|c|c|c|c|}
\hline Allergen & Positive Rate, \% & $(N)^{*}$ & \\
\hline & Conc. 1 & Conc. 2 & Conc.3 \\
\hline Artemisia annua pollen (Group A) & $91.67(11 / 12)$ & $100.00(12 / 12)$ & $100.00(11 / 11)$ \\
\hline Platanus pollen (Group B) & $36.36(4 / 11)$ & $91.67(11 / 12)$ & $100.00(12 / 12)$ \\
\hline Dog dander (Group C) & $100.00(4 / 4)$ & $100.00(6 / 6)$ & $100.00(6 / 6)$ \\
\hline Betula platyphylla pollen (Group D) & $72.73(8 / 11)$ & $80.00(8 / 10)$ & $100.00(11 / 11)$ \\
\hline Cat dander (Group E) & $75.00(9 / 12)$ & $100.00(12 / 12)$ & $100.00(12 / 12)$ \\
\hline Humulus pollen (Group F) & $100.00(12 / 12)$ & $100.00(12 / 12)$ & $100.00(12 / 12)$ \\
\hline Blattella germanica (Group G) & $54.55(6 / 11)$ & $100.00(11 / 11)$ & $100.00(9 / 9)$ \\
\hline Ragweed pollen (Group H) & $30.00(3 / 10)$ & $91.67(11 / 12)$ & $72.73(8 / 11)$ \\
\hline
\end{tabular}

Table 6

Comparison of the diameter of wheal at different concentrations of each allergen in Study $7^{\dagger}$

\begin{tabular}{|l|l|l|l|l|}
\hline Allergen & $\begin{array}{l}\text { Conc.1 (Mean } \pm \\
\text { SD) }\end{array}$ & $\begin{array}{l}\text { Conc.2 (Mean } \pm \\
\text { SD) }\end{array}$ & $\begin{array}{l}\text { Conc.3 (Mean } \pm \\
\text { SD) }\end{array}$ & $P$ \\
\hline Artemisia annua pollen (Group A) & $115.02 \pm 1.59$ & $7.70 \pm 1.75$ & $9.75 \pm 2.50$ & $<0.001^{*}$ \\
\hline Platanus pollen (Group B) & $113.04 \pm 2.19$ & $4.36 \pm 1.25$ & $4.95 \pm 1.40$ & $0.002^{*}$ \\
\hline Dog dander (Group C) & $45.38 \pm 1.30$ & $5.88 \pm 1.76$ & $7.12 \pm 2.14$ & 0.174 \\
\hline $\begin{array}{l}\text { Betula platyphylla pollen (Group } \\
\text { D) }\end{array}$ & $95.03 \pm 3.09$ & $6.86 \pm 3.40$ & $7.33 \pm 3.17$ & $0.008^{*}$ \\
\hline Cat dander (Group E) & $124.06 \pm 1.96$ & $6.14 \pm 1.55$ & $7.52 \pm 1.79$ & $0.001^{*}$ \\
\hline Humulus pollen (Group F) & $127.27 \pm 1.88$ & $11.10 \pm 4.04$ & $11.85 \pm 3.52$ & $0.001^{*}$ \\
\hline \begin{tabular}{l} 
Blattella germanica (Group G) \\
\hline Ragweed pollen (Group H)
\end{tabular} & $93.19 \pm 0.87$ & $4.58 \pm 1.12$ & $5.47 \pm 1.97$ & $0.003^{*}$ \\
\hline${ }^{\dagger}$ Friedman Test & $102.65 \pm 1.32$ & $3.68 \pm 0.64$ & $4.32 \pm 1.74$ & $0.003^{*}$ \\
\hline${ }^{*} \mathrm{p}<0.05$, with statistical significance & & \\
\hline
\end{tabular}

Table 7

Allergens corresponding to the unresolved wheal $24 \mathrm{~h}$ after the prick test

\begin{tabular}{|l|l|l|l|}
\hline Allergen & \multicolumn{1}{c|}{ Group } & 1Group 2Total \\
\hline Artemisia annua pollen & 1 & 4 & 5 \\
\hline Betula platyphylla pollen 1 & 1 & 2 \\
\hline Humulus pollen & 0 & 2 & 2 \\
\hline Cat dander & 0 & 1 & 1 \\
\hline
\end{tabular}

\section{Figures}




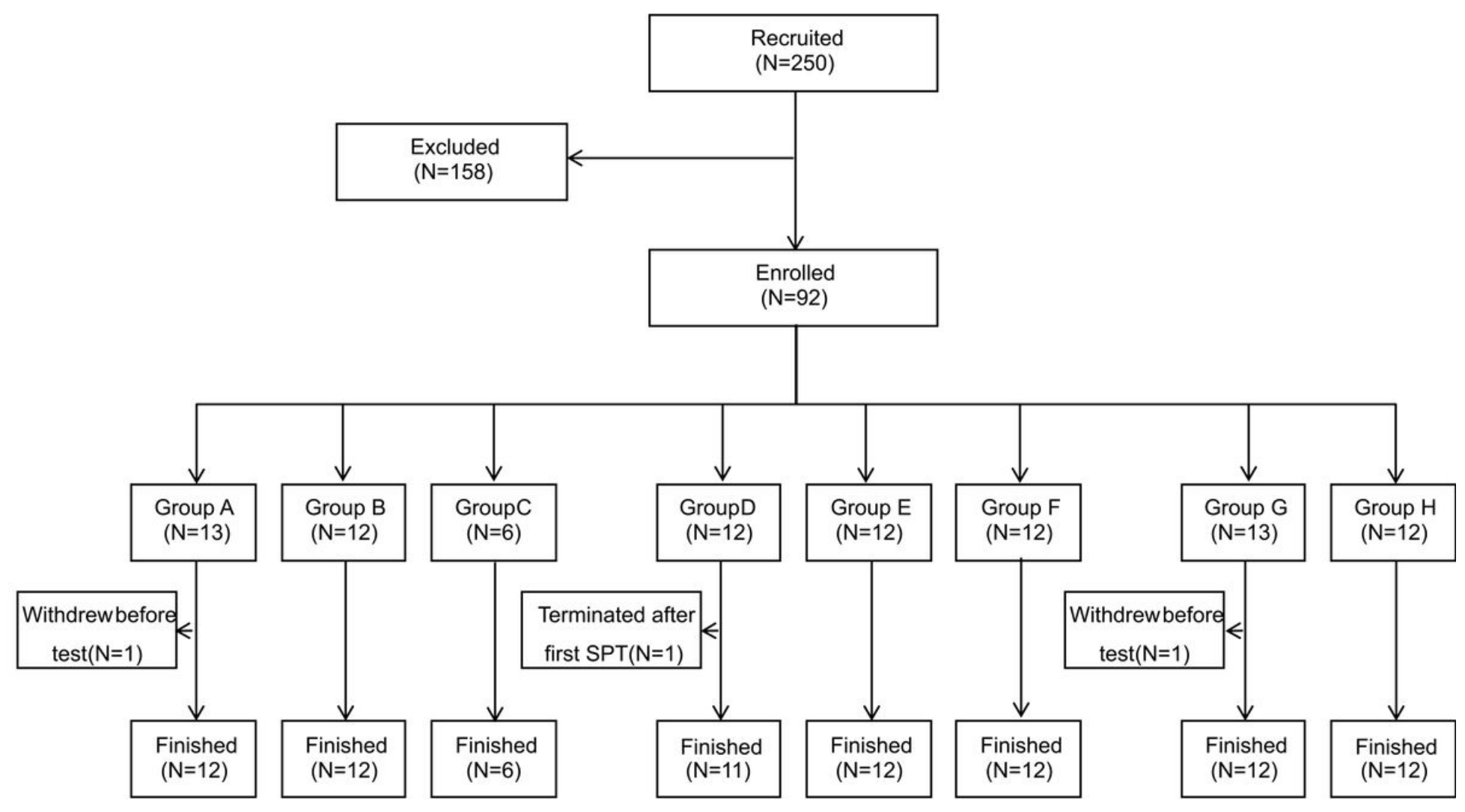

\section{Figure 1}

The flow diagram of Study 1 for the clinical trial of eight allergen extracts in healthy patients 


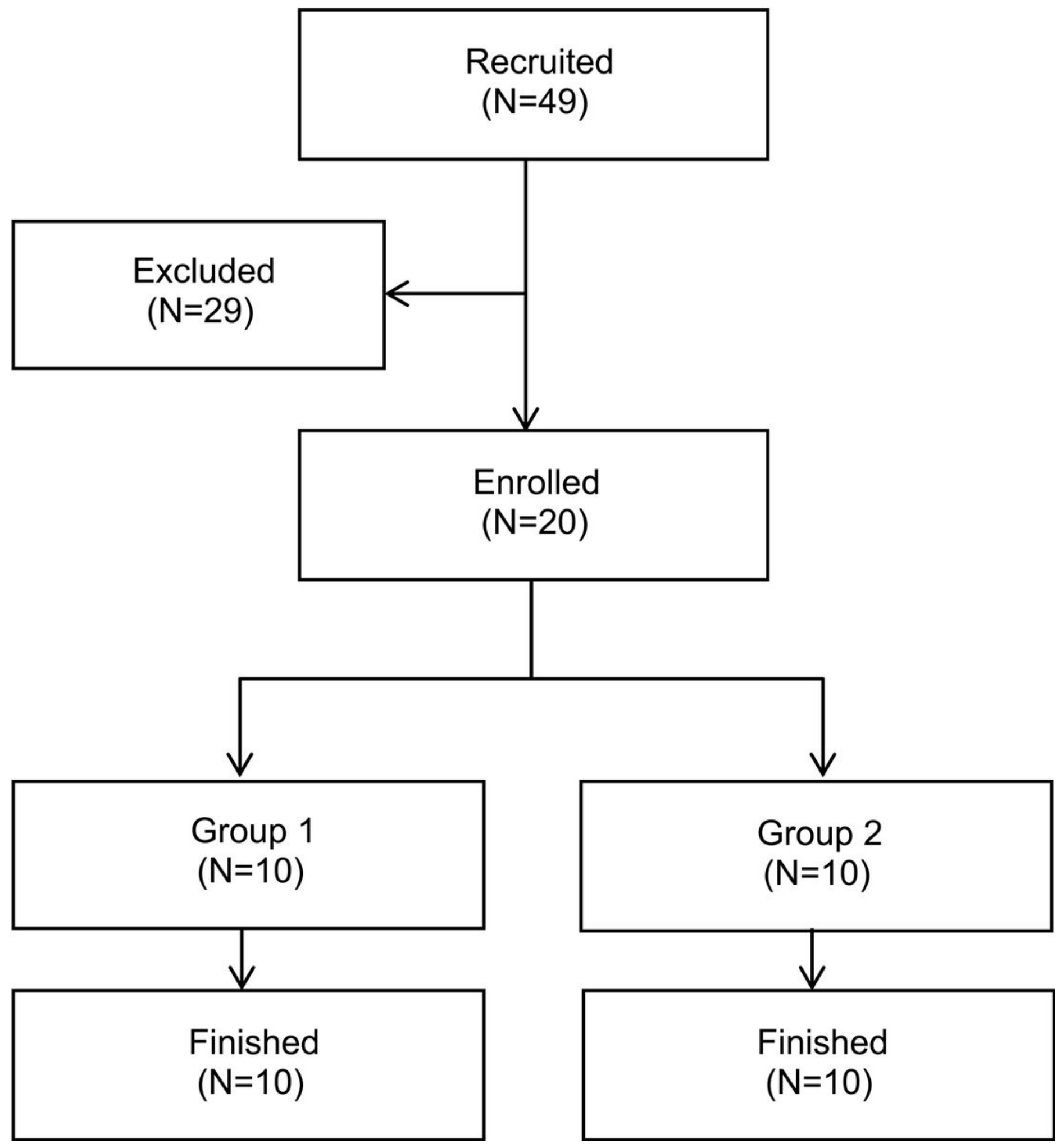

Figure 2

The flow diagram of Study 2 for the clinical trial of eight allergen extracts in healthy patients 
Group A (Artemisia annua pollen)

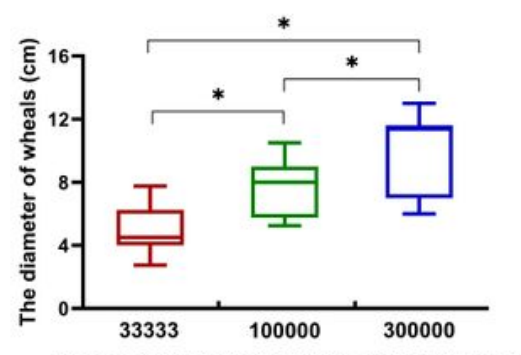

The concentration of allergen extract $(\mathrm{DU} / \mathrm{mL})$

Group C (Dog dander)

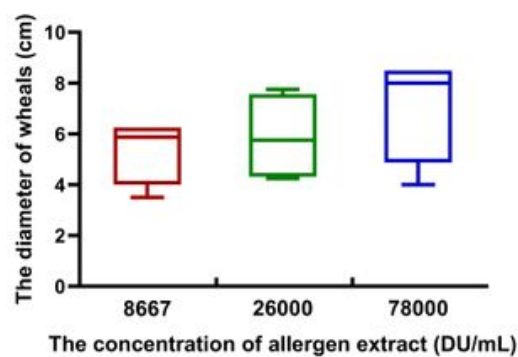

Group E (Cat dander)

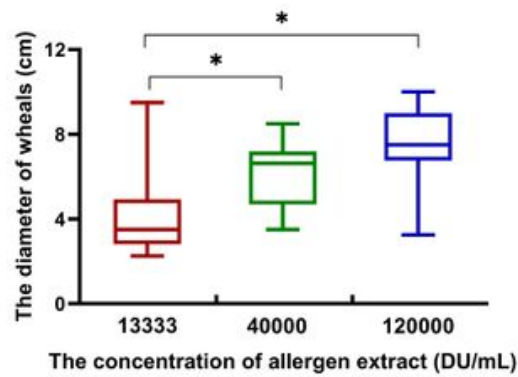

Group G (Blattella germanica)

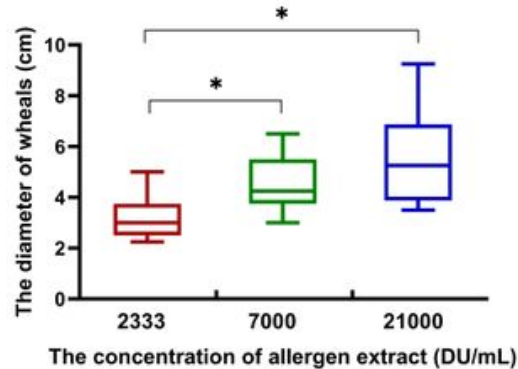

Group B (Platanus pollen)

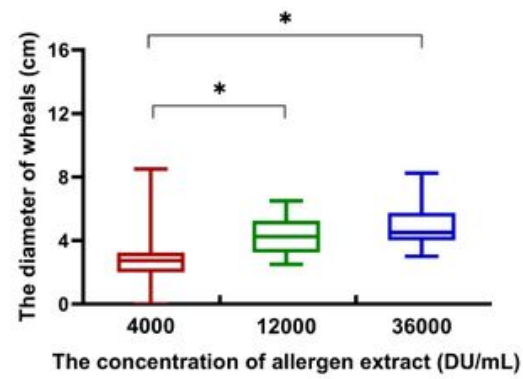

Group D (Betula platyphylla pollen)

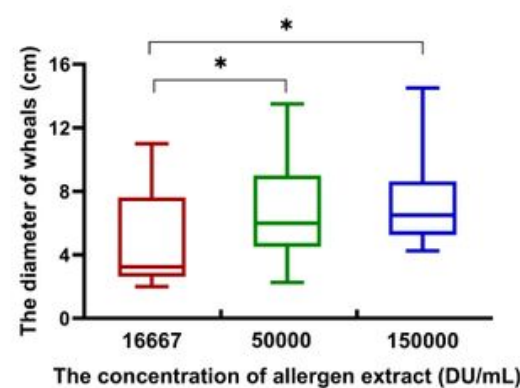

Group F (Humulus pollen)

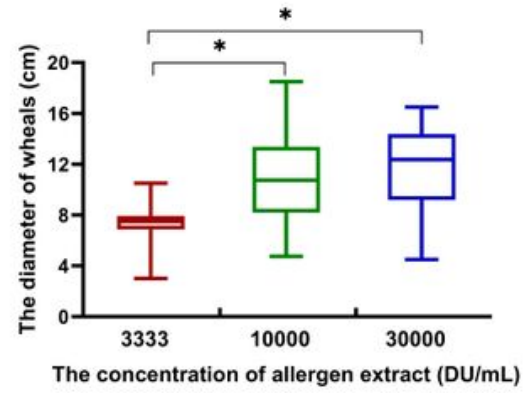

Group H (Ragweed pollen)

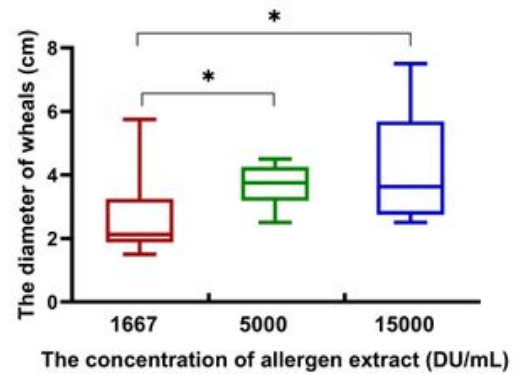

\section{Figure 3}

The comparison of the diameter of wheal at different concentrations of each allergen * with statistical significance 
This is a list of supplementary files associated with this preprint. Click to download.

- AdditionalFilelegends.docx

- Additionalfile2.xlsx

- Additionalfile1.xlsx 